\title{
ORNL /IAT ARMATURE DIAGNOSTICS DEMONSTRATION TEST REPORT: PART TWO: BENCH DEMONSTRATION
}

S. W. Allison, M. R. Cates, S. M. Goedeke Oak Ridge National Laboratory Oak Ridge, TN.

M. T. Crawford, S. B. Ferraro, D. Surls, J. Stewart Institute for Advanced Technology

Austin, TX.

Date Published: Dec 2005

\author{
Prepared by \\ OAK RIDGE NATIONAL LABORATORY \\ P.O. Box 2008 \\ Oak Ridge, Tennessee 37831-6283 \\ managed by \\ UT-Battelle, LLC \\ for the \\ U.S. DEPARTMENT OF ENERGY \\ under contract DE-AC05-00OR22
}




\section{Executive Summary}

The purpose of the present effort was to demonstrate "on the fly" temperature measurement of railgun armatures on a bench top railgun. The effort builds on the previous test that utilized a portable unit with armature speeds ranging from 50 to $90 \mathrm{~m} / \mathrm{s}$. The tests described here involved higher speeds, ranging from 300 to $500 \mathrm{~m} / \mathrm{s}$. The method to accomplish the measurement involves pulsed laser illumination of a phosphor-coated armature. The duration of the ensuing fluorescence indicates temperature.

The measured temperatures, obtained both inside the muzzle and outside in free flight, ranged between 80 to $110 \mathrm{C}$. The required pulsed fluorescence was made possible by successfully sensing the position of the armature while traveling within the laser illumination and fluorescence sensing fields-of-view. A high-speed camera also captured images of the moving armatures after exiting the railgun. These images sometimes included the fluorescing region of the phosphor coating.

\section{Method}

The general method was described in detail in the previous report. In summary, a single pulse of $337 \mathrm{~nm}$ nitrogen laser light is timed to strike a phosphor coating on a moving railgun armature. The resulting fluorescence waveform is collected and analyzed to yield the temperature of that illuminated spot on the armature surface at the time of the laser flash.

\section{Test Description}

The railgun is depicted in Figure 1 as it is being prepared. After several firings, the muzzle was modified to accommodate optical fiber probes. Figure 2 provides additional views. The bottom frame reveals the location of the two fiber probes. One senses the arrival of the armature, and the other delivers the excitation laser light and captures the fluorescence, directing it to a detector and data acquisition system.

The armatures were prepared by removing approximately $1 \mathrm{~mm}$ of material from the top, resulting in a slight depression so as not to interfere with normal use. The phosphor paint mixture was applied which consisted of 3 parts Sperex paint binder to 2 parts phosphor. Fluorescence from the two types of test phosphors is seen in figure 3 . The phosphor on the left, $\mathrm{Gd}_{2} \mathrm{O}_{2} \mathrm{~S}: \mathrm{Eu}$, appears slightly redder than the $\mathrm{La}_{2} \mathrm{O}_{2} \mathrm{~S}: \mathrm{Eu}$. The $\mathrm{Gd}$ phosphor was used for most of the shots because its higher temperature range made it more useful than the $\mathrm{La}$ phosphor. The armatures were air cured several weeks before the test. After one or two shots the coatings significantly degraded. Upon learning this, additional armatures were coated and heat cured with a laboratory heat gun. These coatings survived much better.

Figure 4 shows the free flight measurement station. The trigger fiber probe views the side of the armature rather than the top as its muzzle counterpart. The illumination and viewing fiber probe is arranged above the flight path and looks down. Figure 4 shows an armature placed underneath the probe and the fluorescing spot of the coating is evident. 
Figure 5 shows a block diagram of the experimental apparatus. The approach is similar to the earlier test but is rendered more complex by an additional measurement channel. Thus, there is an additional laser, photodiode, oscilloscope, etc.

Another difference between this test and the earlier is that the triggering fiber and the fluorescence pickup fiber were positioned so that no timing delay was necessary. That is, when the armature arrived to the triggering beam, the fluorescence receiving fiber was directly over the phosphor coating.

The first triggering method for the external location involved directing a continuous red laser beam across the flight path to a photodiode. This produced a strong signal which decreases significantly when the armature moves between source and detector. The photodiode connected to an amplifier (Melles Griot 10 Model Amp003 Large Dynamic Range amplifier) whose output was directed to a trigger generator. The trigger generator, having controllable trigger level and delay capability, produces a TTL pulse that initiates the laser. Efforts to shield the photodiode from ambient light and from the lamps providing illumination for the high-speed camera lights were successful. A short section of PVC pipe served as a cowling for this purpose. The signal output of the amplifier for the first shot is shown in figure 6 . Prior to the arrival of the armature, by about $1 \mathrm{~ms}$, what is presumably an air slug passes through the beam, producing a slight increase in transmitted signal. This did not hinder proper triggering. However, the amplifier time response was slow, requiring about 50 microseconds to reach the full width half maximum value, as seen in the inset. Given that at $500 \mathrm{~m} / \mathrm{s}$ the armature could move about $10 \mathrm{~cm}$ in this amount of time, this delay may have been responsible for not capturing a fluorescence signal. Next, two changes were made to the setup. The amplifier was replaced with different, faster model (Melles Griot Model 10 Amp005 Wide Bandwidth Amplifier). And, the trigger method was changed.

A reflective approach to triggering was implemented both in the bore of the railgun and outside in the free flight region. A bifurcated optical fiber is used whose output end consists of two closely spaced fibers that are placed as close as possible to the flight path. Trigger light, as before, emerges from one fiber. When the armature passes in front of this fiber pair, the laser light is reflected into the other fiber and conveyed to the photodiode. Thus, there is a very low signal until the armature passes in front of the fiber. Figure 7 shows a representative signal. A small fluctuation occurs before the armature arrival. When the trigger level is set sufficiently high, this is not a problem. For inside the bore measurements, the triggering fiber pair stares down from above. For the free flight path station, the armature is probed from the side. This arrangement produced a successful trigger some of the time. Figure 8 shows one of the earlier amplified photodiode signals (shot 6) for the in-bore position. Originally we thought this had to do with the nature of the electrical/optical environment inside the bore. It appears to have a different character than figure 7 . But it turned out that it was due to a faulty amplifier. Consequently, only one photodiode amplifier was in consistent working order and we were not able to successfully capture data both inside and outside the gun on the same shot.

\section{RESULTS}

Figure 9 shows four successive images of the armature in flight. This was shot \#6. The first frame is prior to arriving at the measurement station. The second and third frames clearly 
reveal the fluorescing spot. By the final frame, the armature has emerged into the illumination of the camera light so that the entire coating appears white, simply from reflectance. Shot 10 results, depicted in figure 10, are similar. Figure 11 shows the fluorescing armature as it emerges from the muzzle for shot 17.

The temperature determinations are given in the table. The top three results are for measurements outside the muzzle and were obtained using the first rail pair, Figure 12. These rails apparently did not experience transition during their fifteen shots of operation.

Table 1 Measured Temperatures

\begin{tabular}{|l|l|l|l|l|l|l|}
\hline & Shot \# & Voltage & $\begin{array}{c}\text { Velocity } \\
(\mathrm{m} / \mathrm{s})\end{array}$ & $\begin{array}{c}\text { Armature } \\
\#\end{array}$ & $\begin{array}{l}\text { Rail } \\
\text { Pair }\end{array}$ & $\begin{array}{c}\text { Temperature } \\
\mathrm{C}\end{array}$ \\
\hline Outside & & & & & & \\
\hline & 6 & 300 & 486 & 5 & 1 & $92+/-4$ \\
\hline & 10 & 300 & 439 & 21 & 1 & $84+/-4$ \\
\hline & 11 & 300 & 462 & 22 & 1 & $92+/-4$ \\
\hline Inside & & & & & & \\
\hline & 23 & 300 & 478 & 23 & 2 & $112+/-6$ \\
\hline & 31 & 275 & 383 & 23 & 2 & $92+/-4$ \\
\hline & 28 & 250 & 345 & 23 & 2 & $90+/-4$ \\
\hline
\end{tabular}

It may be noted that for a firing to acquire useful data, not only was it necessary for the triggering to be correctly set, but the oscilloscope gain and time base settings had to be properly anticipated. Thus some of the firings were expended getting these adjustments right. The fluorescence signal for shot 11 from the outside position is shown in figure 13 . An exponential signal with a decay of $4 \mu \mathrm{s}$ is plotted through the data for comparison. Based on an uncertainty of $+/-1 / 2 \mu \mathrm{s}$, the temperature is $92+/-4 \mathrm{C}$. The motion of the fluorescing spot during the measurement did not appear to be a significant problem with the outside data. The small deviation of the signal at around $8 \mu$ s might be due to this.

Motion was more significant for the in-bore data. In addition, owing to the nearby surfaces, laser scattering into the receiver fiber was more of a problem. These issues were surmounted. The in-bore measurement is illustrated in figure 14 for shot 23 . The green trace is the temperature dependent fluorescence signal. The signal falls more rapidly from its maximum out to nearly 2 microseconds than it does subsequently. This early portion of the signal is ignored. The red trace is the signal from a temperature independent emission line. For a stationary source its amplitude level will not change significantly over the $10 \mu$ s range depicted. Thus the decrease is due to moving out of the field of view of the collection fiber. The early part of the pulse is also affected by laser light scattering into the fiber and getting through to the photomultiplier. Shot 22, immediately prior to this shot, was a "blank," where the armature used had no phosphor-coated surface. The backscattered signal at the red wavelength was acquired and subtracted from shot 23 in order to perform a correction. The result is the yellow trace. The yellow trace is essentially flat out to about four and a half microseconds. The smoothed curve through it, a dashed blue line illustrates this. This result 
indicates that the signal within the flat region may be used to indicate temperature. Figure 15 shows the temperature-dependent signal with a representative $2.6 \mu$ s trace through the data up to about $5 \mu$ s. An uncertainty of $\pm 0.4^{\circ} \mathrm{C}$ implies a temperature of $112 \pm 6^{\circ} \mathrm{C}$.

Because the rate of heating of the armature during firing takes place over a few milliseconds, the phosphor coating on the outside surface, when pulsed by the interrogating laser, may not be exactly the same as the temperature of the conducting body of the armature. The surface temperature measured depends to some extent on the thermal conductivity of the phosphor layer. These layers are very thin, however, and are expected to conform to the bulk armature temperature in times comparable to the flight times. Careful laboratory calibrations can quantify any uncertainties related to these time-dependent effects, and will be especially useful to determine optimum phosphor thickness for future work.

\section{CONCLUSIONS}

The data indicate that temperature scales with voltage as seen from data from inside the muzzle. The velocity, in turn, also scales with voltage though there is shot to shot variation. The data for the three free flight path shots were all for the same voltage, $300 \mathrm{~V}$, and show a temperature dependence in correspondence with the shot-to-shot variation in velocity. For the same voltage, $300 \mathrm{~V}$, the temperature inside the bore was hotter, $112 \mathrm{C}$, than for the free flight. This could be due to several things. There may be some cooling (as a result of aerodynamic effects) during the approximately $1 \mathrm{~ms}$ of flight from the muzzle to the outside measurement position. On the other hand, the rails used for the listed inside measurements were different than those used for the listed outside measurements. The characteristics of the rails could also have an influence on the temperature. Observe that the outside temperatures are comparable to the inside temperatures for lower voltage and velocity operation.

There are several lessons learned from the effort. First, there is room for improvement in triggering. A brighter laser trigger source could help to some degree, especially in overcoming the effects of ambient light. The weakest link in the chain of components was the amplifier used between photodiode and trigger generator. The frequency response (up to $1 \mathrm{MHz}$ ) of the amplifier scales with the sensitivity, thus producing a higher photodiode signal will be beneficial. In addition, implementing larger core diameter fibers would also deliver and receive more light and yield positive results, especially in improvement of the signal-tonoise ratio.

The fiber probe inserted into the gun consisted simply of two side-by-side 600 micron fibers. Using a fiber bundle consisting of, for instance, a 2 by 10 rectangular array of 600 micron fibers plus an extra fiber for laser delivery should thereby increase the signal by a factor of approximately twenty. This would serve two purposes. It would allow the probe to be raised higher above the flight path, thereby decreasing the amount of laser light scattered into the receiver fiber. It would also serve to stretch out the time over which the fluorescence may be viewed without motion effects. A drawback would be that it may require a slot rather than a hole to be drilled into the railgun.

It is realized that an important goal of this effort, eventually, is to measure temperature distributions on an armature. Based on the experience in the test described here, it appears 
that attempting to do this by measuring different points on an armature for different shots, though possible, would give rise to many difficulties. Two or more points on the moving armature can be measured by applying separate fiber systems during a particular firing. It may be possible to split the pulsed laser beam to strike two or more places simultaneously along the armature. Possibly, however, the best approach to this temperature distribution measurement would be to use imaging. An imaging system would acquire a snapshot of the moving armature and provide a temperature profile. We have a collaborator at NASA Glenn who has the right kind of camera systems and software for performing fluorescence-based thermometry. He typically uses this for aerospace applications and has offered to provide us assistance, even loaning the equipment for future testing.

In conclusion, the tests successfully determined temperature for armatures under several different operating conditions. With some additional effort, this diagnostic can be applied to other railgun test beds.

All of the authors wish to thank the manager of the United States Army Electromagnetic Gun Program, Mr Matt Cilli, for funding this activity.

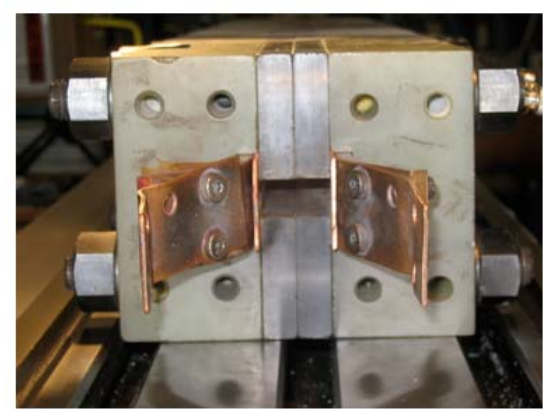

Rail Gun exit without shunt
Figure 1 Benchtop railgun

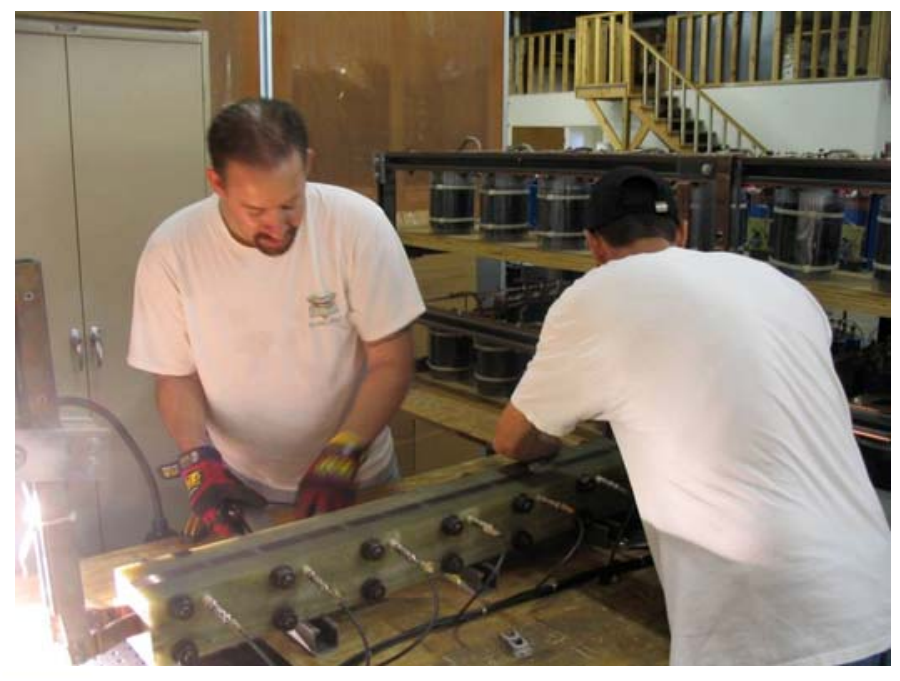

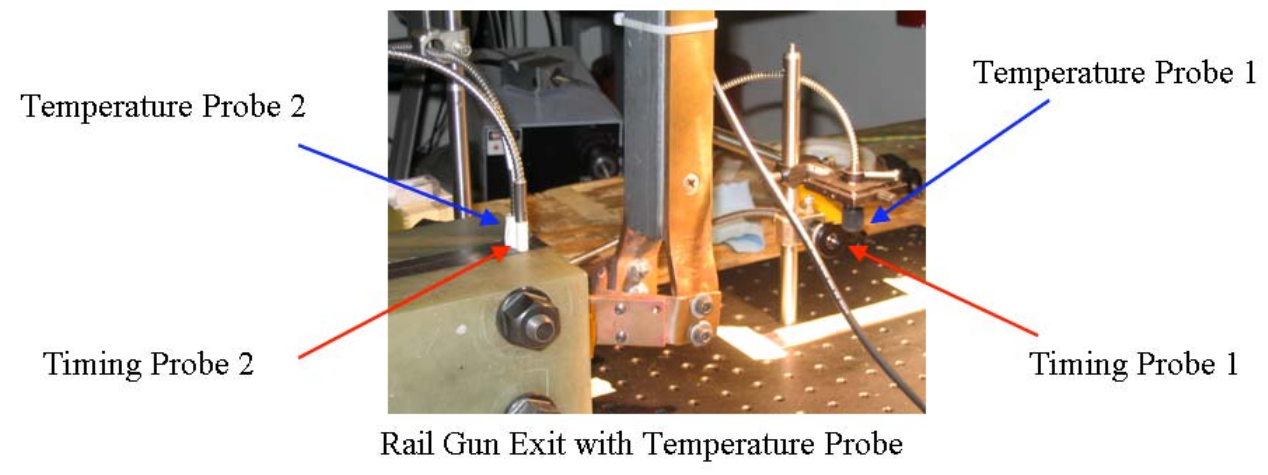

Figure 2 Views of railgun 


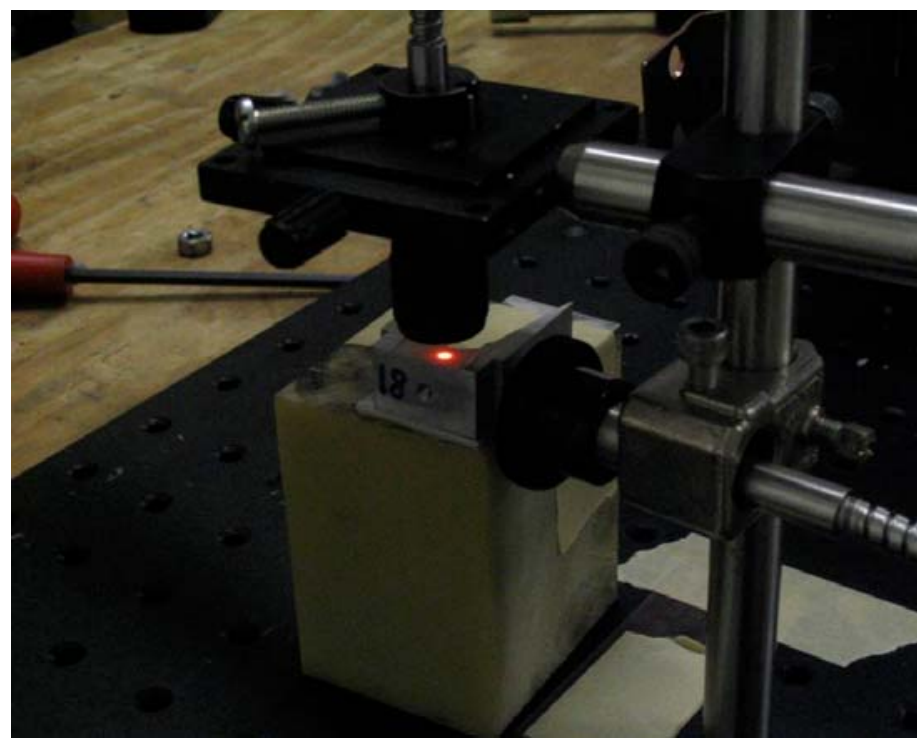

Figure 4 Fluorescing spot on stationary armature

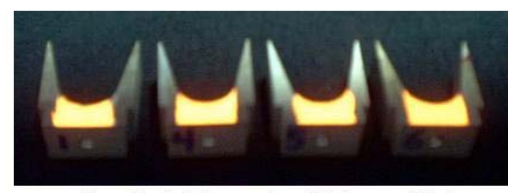

$\mathrm{La}_{2} \mathrm{O}_{2} \mathrm{~S}$ :Eu under $302 \mathrm{~nm}$ Light

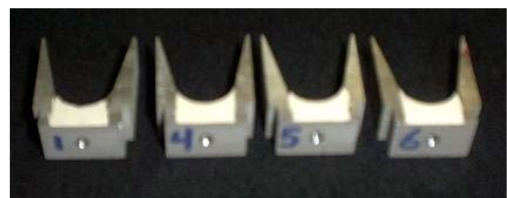

$\mathrm{La}_{2} \mathrm{O}_{2} \mathrm{~S}$ : Eu under White Light

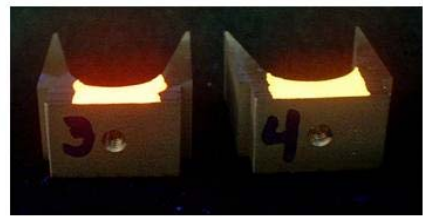

$\mathrm{Gd}_{2} \mathrm{O}_{2} \mathrm{~S}: \mathrm{Eu} \mathrm{La} \mathrm{O}_{2} \mathrm{~S}: \mathrm{Eu}$

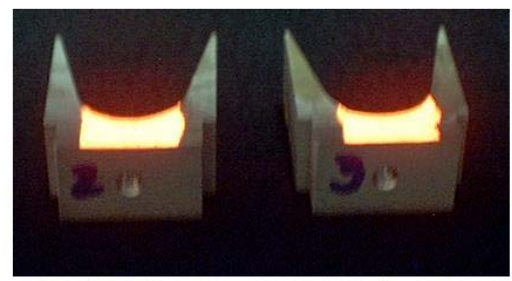

$\mathrm{Gd}_{2} \mathrm{O}_{2} \mathrm{~S}$ :Eu under $302 \mathrm{~nm}$ Light

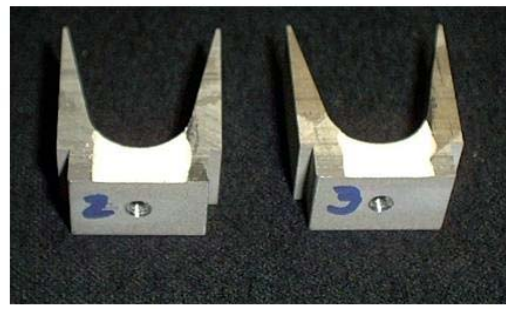

$\mathrm{Gd}_{2} \mathrm{O}_{2} \mathrm{~S}$ :Eu under White Light

Figure 3 Coated Armatures

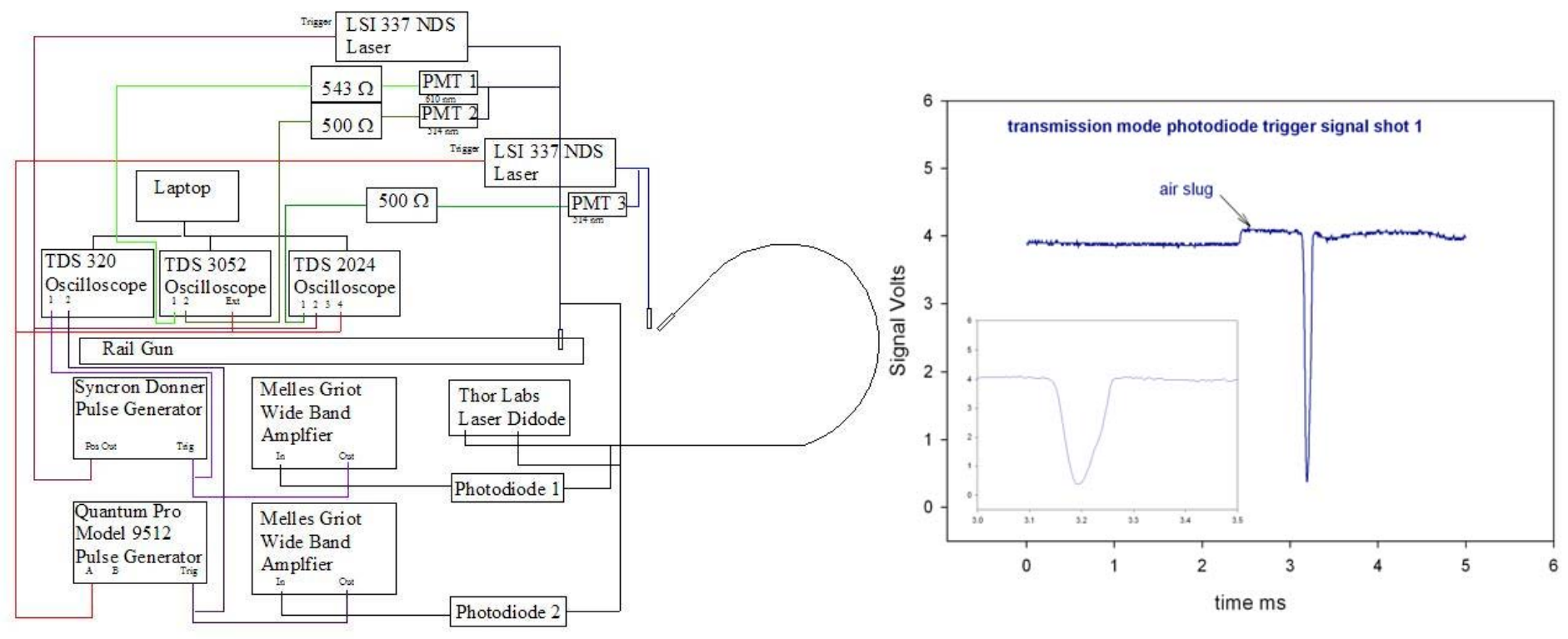

Figure 6 Outside Photodiode Signal Transmission Mode

Figure 5 Block Diagram 

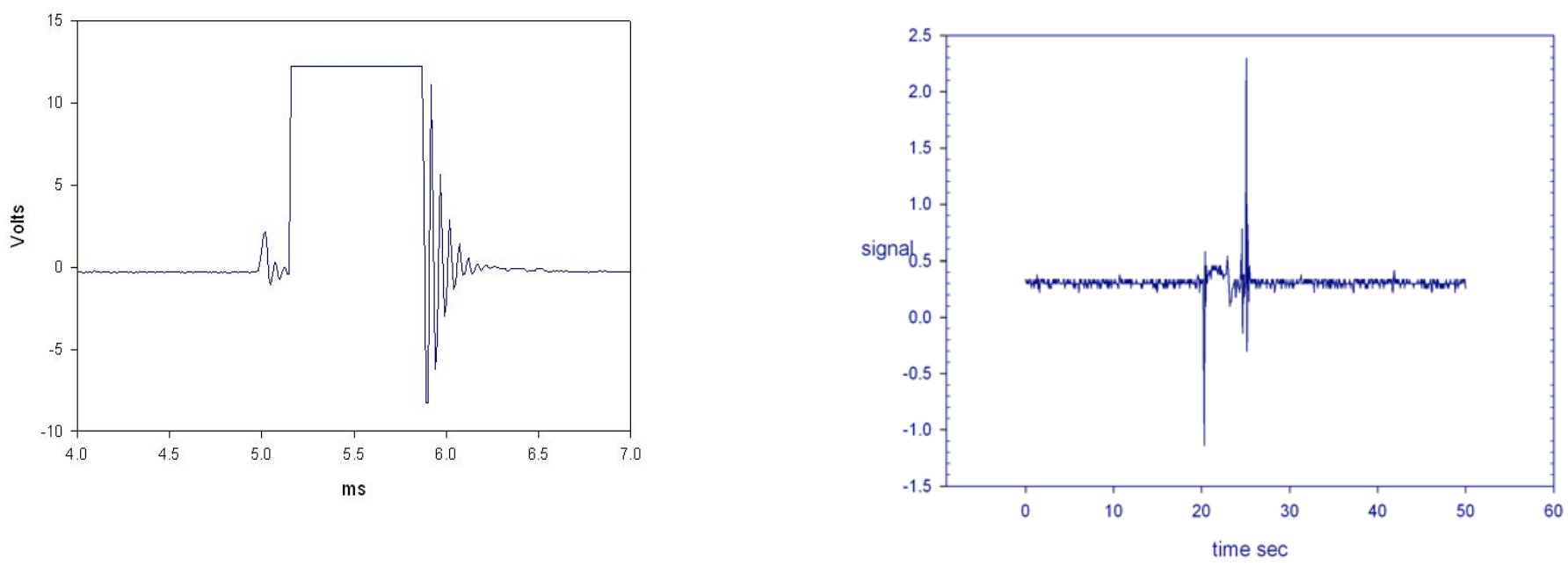

Figure 7 Outside High Speed Photodiode Reflective Mode Figure 8 Inside High Speed Photodiode Reflective Mode

\section{Images from High-Speed Camera Shot 6}

Armature before

Temperature Probe 1
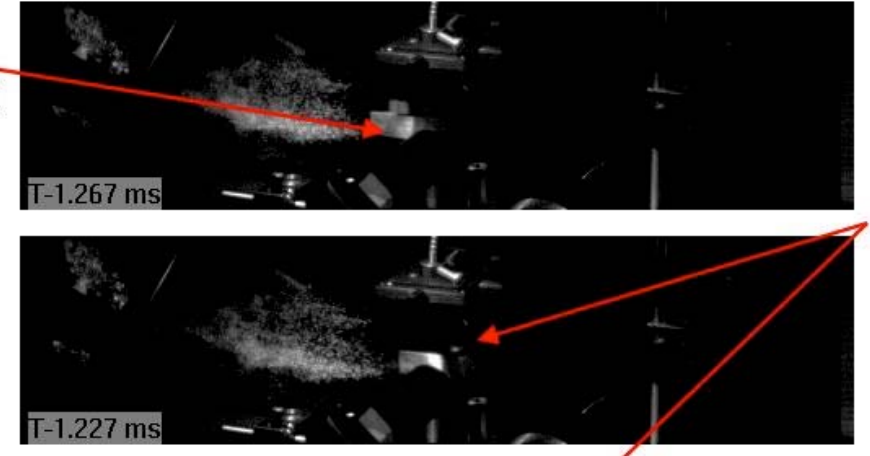

Excited phosphor

on armature
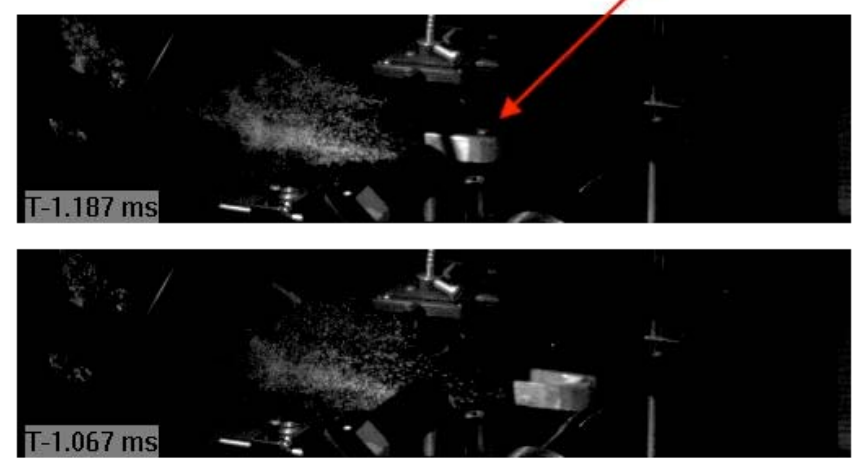

Figure 9 Shot \#6 Images 


\section{Images from High-Speed Camera Shot 10}

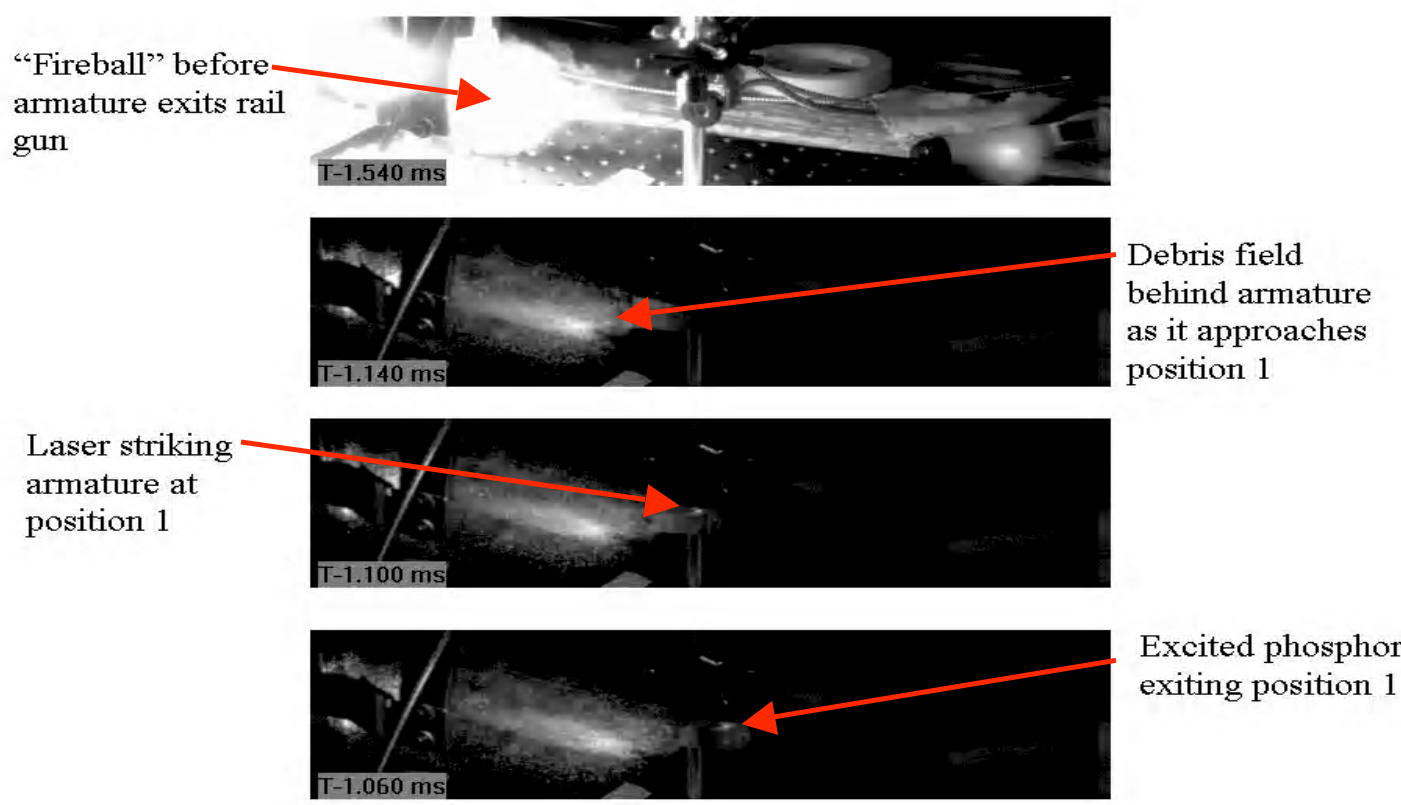

Figure10 Shot \#10 Images

\section{Images from High-Speed Camera Shot 17}

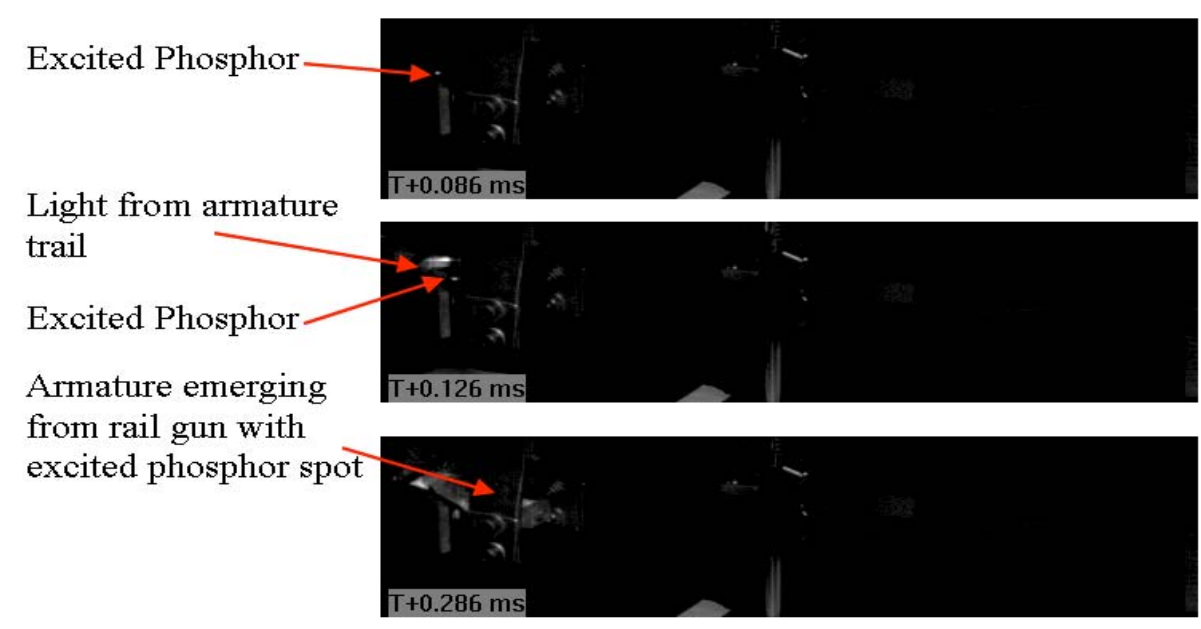

Second shot on new rails. Very little debris behind armature.

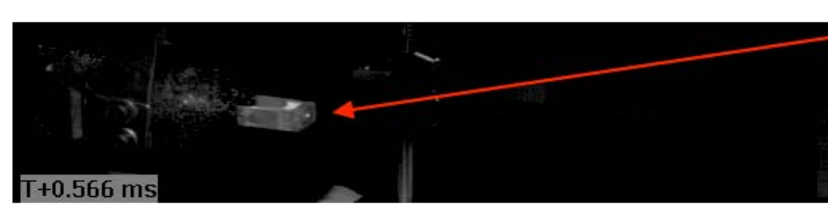

Armature between

Positions 1 and 2. 


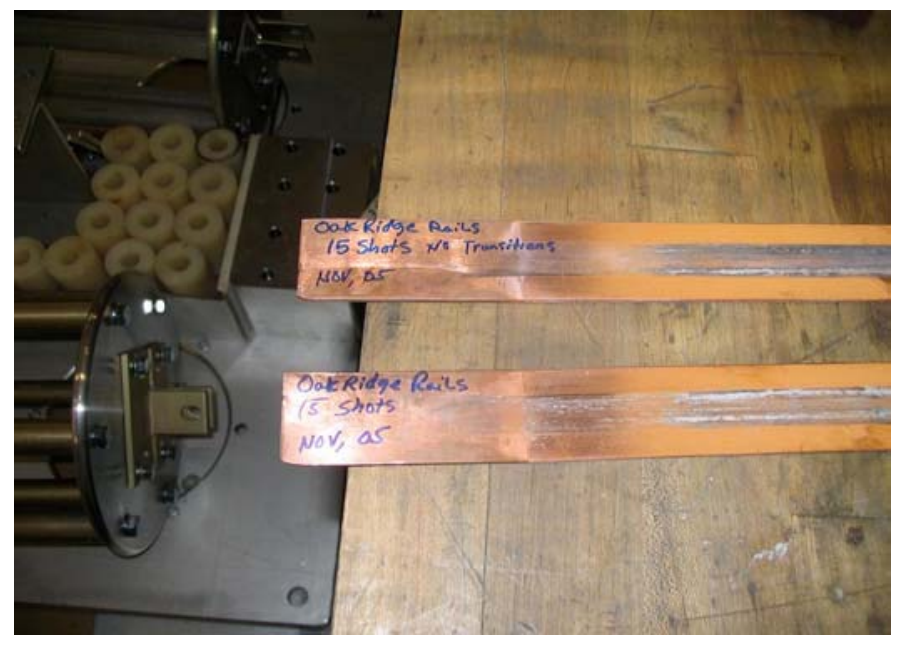

Figure 12 Rail Pair for shots $1-15$

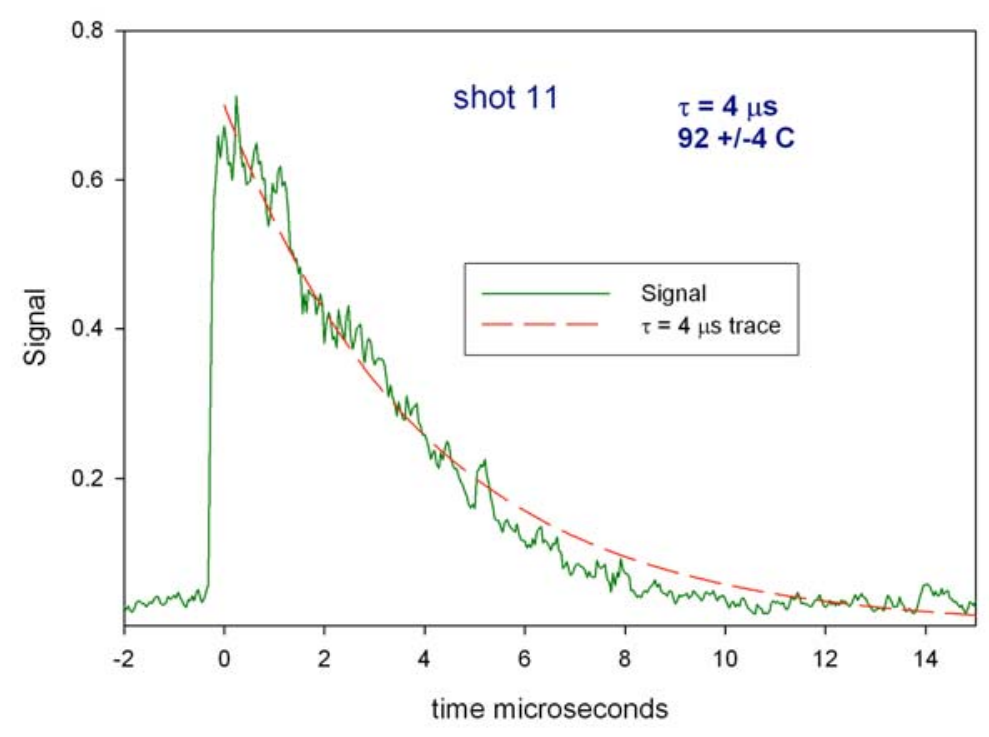

Figure13 Signals for shot \#11 outside

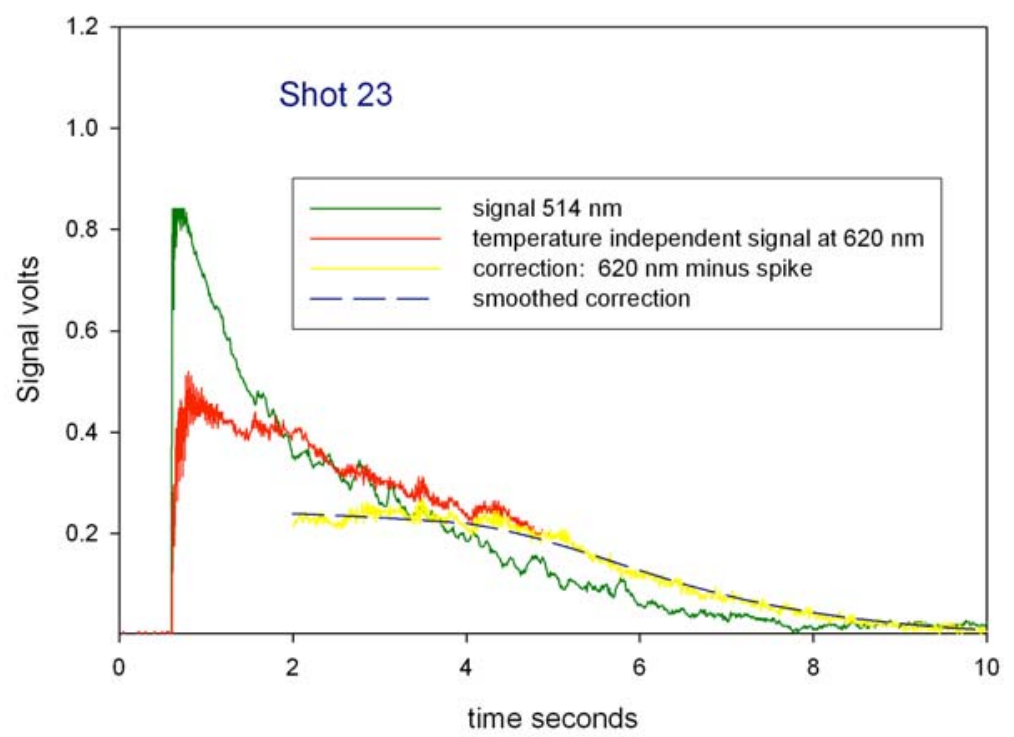

Figure14 Signals for shot \#23 inside

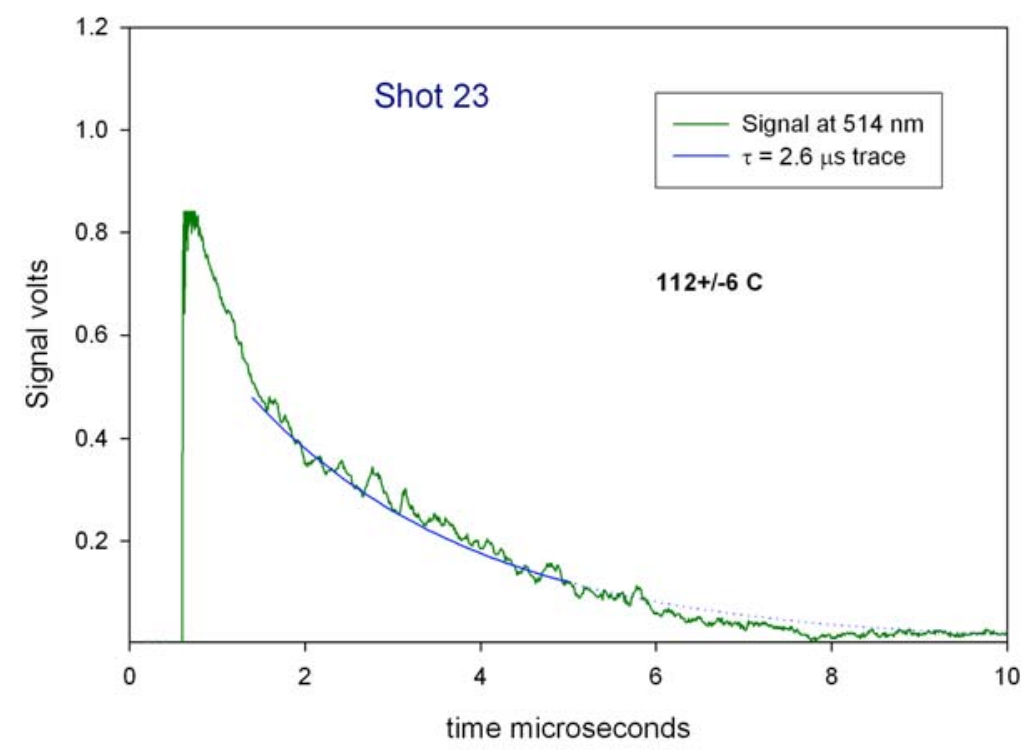

Figure15 Fit to shot \#23 inside 